\title{
September in York
}

\section{Council and General Meeting}

Even before the 4th General Conference began, Council had met in lengthy session following a marathon meeting of the Executive Committee the day before. On the Tuesday evening, 26 September, ten years to the day after the foundation of the European Physical Society, the 4th General Meeting was held and as the ground covered was similar to that covered at Council, the following report is a synthesis of the two events.

The President in opening the two meetings, as he had done when interviewed for Europhysics News (see September issue), laid stress on the need to think always of unification, and actively to seek those areas where collaboration between diverse peoples was possible, rather than dwell on the difficulties that can arise. $\mathrm{He}$ took his inspiration from this year being the hundredth anniversary of Maxwell's unification of electricity and magnetism, and the year in which the Salam and Weinberg gauge theory, had received such strong experimental support that one could say with almost certainty, that electromagnetism and the weak force were two facets of the same fundamental force of nature.

\section{EPS and Education}

One area where EPS had an expanding role to play was in the promotion of internationalism in education. Current activities included the study made by the Advisory Committee on Physics Education of secondary school teaching in the various European countries, and the EPS Scholarship Scheme whereby, starting this autumn, a number of students at the post graduate level would be able to continue their studies in a country other than their own. The scheme had been launched following the Council's call for action in Helsinki and now needed to be consolidated. It was evident that the scheme was not well known among students, nor amongst universities, and that we had only begun to tap the potential interest. Professor Jean Muller of Geneva has agreed to take the responsibility for coordinating the search for more places and encouraging the dissemination of information to students, so that the Society could look forward to the time when it was embarrassed by the number of applications. Suggestions that the scheme should be thrown open to non-Europeans were regarded as premature. EPS with a great deal of thought has drawn up its rules covering the scholarship scheme (EN, 1978, April, p. 3) and only when this scheme was thoroughly established, could one consider how it might be extended to the third world.

The latest project concerned the exchange of lecturers between European Universities which in many respects was more complex than the awarding of scholarships. Not only must there be a teaching position which the visitor could fill but there must also be a research team into which he can slot quickly and effectively over the period he will be there. The Physics Education Committee is looking into the problems and will be formulating proposals in the coming months.
The Executive Committee of EPS has now agreed to participate in the deliberations over the establishment of a European University for Pure Science (a title that no one liked, but titles are not important at the moment) and a Polytechnic to serve the Mediterranean region. Warnings were voiced that the Society must guard against encouraging the establishment of new bureaucracies. One of the features of these present times seemed to be the proliferation of new international institutions, each with its own bureaucracy, the result being increased time spent on administration and less time spent on physics. (Happily in this context the minute Secretariat of EPS was a model to other Institutions.) Concern was also

\section{Contents}

September in York

Council and General Meeting

Conference Impressions

Physics in Society

The Arms Race

Communication

Developing Countries

Technical Notes

Modern Optics

A Different Facet

Phase Transitions

Bio-energetics

Heavy Ions

Quarks and Jets

Surfaces and Experimental

Techniques

Education and Popularization

New I.O.M.s.

1
4
5
6
6
8
9
10
10
12
12
13

14
15
16


expressed that participation in such activities gave tacit approval to the basic ideas but it was generally agreed that if EPS did not participate in discussions, it had no opportunity to model or mould the final outcome. What was important was to get the basic thinking right. There were an enormous number of implications in founding a new University system which would be an institution that should last for a very long time. Considerable emphasis was also given to the necessity of associating research with teaching and equally teaching with research, an aspect of the inter-relationship that seems to have been neglected in setting up the very large independent research organizations that now exist. It was, even so, important to realise from the beginning that no individual research project would have a life that was at all comparable with that of a new educational institution. Questions of finance too will arise but at least in this instance, EPS can leave that problem to others and can concentrate on bringing its wisdom to bear on the fundamental aspects of European educational institutions.

\section{Constitutional Questions}

In the field of conferences where EPS has had so much success in bringing order to the European scene, the problems are not always simply scientific. Over the past twelve months, ten conferences had been approved and EPS had sponsored 22 conferences and three schools. EPS is associated with $40 \%$ of all the international meetings held in Europe in that period. One conference, however, could not be approved because it did not conform with the EPS rules. The Condensed Matter Division had been proposing to hold a conference in Moscow but not all the required conditions of access could be satisfied and the problem was referred to the Executive Committee, which had no alternative but to refuse the approval requested. In Council, delegates of the Individual Ordinary Members expressed themselves forcibly on the subject, but this was not the only problem with political overtones the Executive Committee had had to consider and the Secretary explained the consistent policy it had adopted in the following terms:

When problems arise, we start by using our contacts within the Society which we have built up over the years. We do not shout our discussions from the house tops, otherwise consultation would quickly become confrontation, but we do act, and a great deal of effort is put into trying to find a solution that can satisfy everyone. Sometimes that proves to be impossible and we then have to operate in a more formal way.

The Society has a number of rules starting with the Constitution and the By-Laws. These were worked out with great care and after much discussion by our founding fathers and we have adjusted them as the years have gone on, in the light of experience and when there was a wide consensus that modification was necessary. We do not try to make new rules to suit each occasion even if a new circumstance arises that was perhaps not envisaged when the rules were written. Indeed, in the case of the Constitution, we cannot make a change except after very formal procedure. Similarly, when we come to operational rules, we must abide by these unless the question is entirely trivial and no one objects to a modest derogation. The rules governing the approval and sponsorship of conferences, as those governing the acceptance of membership, were not worked out overnight, but after much discussion. It is the duty of the Executive Committee to see these rules applied and to see that there is the widest consultation before any changes are made. "Instant government" on the part of the Executive Committee was not what our members want or would even tolerate. This does not mean that as people we are insensitive to the human problems that may be involved, but responsibilities must be put before emotions.

One change in the Constitution that Council did agree should be voted on in Rome, concerned membership of the Executive Committee, as it had been realised that Article 19 , Section 2, did not reflect the intention of the founders. This section is designed to limit the term of office of a member of the Committee to a five-year stretch, but it was not meant that members should then be banned for life from serving again. The exact terms of the proposed amendment will be published in the December issue.

\section{Frequency of General Conference}

The Conference Committee has been looking into the question of how often the General Conference should be held. Opinions cover almost the complete spectrum but it would seem that the general consensus for the present is that three years is a good compromise and we can, as a result, look forward to the next General Conference taking place in 1981.

\section{EPS and Publishing}

One more journal has been added to the list of Europhysics journals. This is the journal Acustica that is published by S. Hirzel Verlag of Stuttgart, with, as Chief Editor, Professor M. Grützmacher of Braunschweig. One further journal remains to be considered, namely the International Journal of Electronics.

Negotiations with The Institute of Physics of the UK over the publication of a new journal were nearing completion. This would be a journal of the EPS published by The Institute of Physics and would cover education at University level, and scholastic studies. The journal would have an editorial board of 20 members of whom 10 would be nominated by EPS, 6 by The Institute of Physics and 4 coopted by the Board itself. Current discussions centred on a 50/50 financial participation, in a project which is estimated to become profitable after 10 years i.e. when accumulated income overtakes investment. The title of the journal has not yet been chosen but the principal Editor has been designated as G.W. Series of Reading University.

\section{Divisional Questions}

No firm conclusions were arrived at as to whether EPS should set up a new Division to cover medical and biophysics. It was generally agreed that we should try to incorporate our colleagues in these fields into the broader physics community, but it seems evident that these two fields are not too well defined and were themselves rather incompatible. It is evident that more thought will have to be given to defining how such a Division should be structured and to what extent the biophysicists should be drawn from biology, and where exactly the hospital physicist is situated. To clarify these points, a Workshop is being arranged at Erice so that representatives of these various fields can participate in the presentation of a firm proposition.

No further steps either have been taken in the definition of the Society's role, vis-à-vis the European Optical Society and whether this should become a Division. Contact has been made with the Society and observers from EPS will be invited to attend meetings, but the wider implications have been allowed to float.

Integration of the Divisions into the overall work of the Society was not always an easy task, yet the Divisions were essentially the life blood of the Society. We had been operating for 
so many years with a large overdraft (see below) that only now could one begin to reconsider different ways in which the Divisions might be supported and how the capitation fee, now the young physicists solidarity fee, which is levied on participants at EPS approved conferences, could be replaced by another financial source. It was also necessary to consider just how functions such as Study Conferences with only a small number of participants could be supported when there was not a large subsidy or income from the participants. Often in organizing conferences in the Divisions the need was for guarantees more than specific funds and this too has to be borne in mind.

\section{EPS and Big Science}

Serious reservations were expressed in Council over the implications of the Executive's proposal to organize at the next Council Meeting in Rome at the end of March, a scientific meeting at which the European big science projects would be presented. It was pointed out with some force that even nationally there was a basic distinction between the functions of a learned Society, which was concerned with the promotion of the science and the maintenance of standards, and the decision-taking organs that considered and managed big projects. If EPS tried to intervene in the management of international projects it would find its interference resented and its influence so small that its credibility in other areas diminished. On the other hand, it was acknowledged that channels of communication on big international projects could be very much improved and it was necessary that European physicists knew what was being proposed in big science and could thereby have the opportunity of commenting on trends, utilisation, competing priorities and so on. At the national level, the decision-making organizations were already advised by individuals in the science community, exercising a role different from their function in the national society. The point really at issue was the extent to which EPS as an organization should try and identify itself with future international developments.

So far, no long term commitments have been made as to the Society's policy, but it was agreed that the meeting in Rome should go ahead as a two-day scientific symposium, during which participants could bring themselves up to date on the five projects of: JET, the European Synchrotron Radiation Source, the Milli- metre Wavelength Radio Interferometer, the NUK Fixed Target Superproton Synchrotron, and LEP, the Electron Positron Colliding Beam Facility. Details of this meeting, timed to coincide with Council will be finalized in the near future.

\section{Financial Position of EPS}

It was a source of satisfaction to all to hear the Treasurer compare the financial position of EPS today with that of the Society at the last General Meeting in Bucharest when we had an accumulated deficit which exceeded 100000 Sw.Fr. This has now been substantially eliminated. The income forecast for 1978 of 410000 Sw.Fr., in purchasing power, corresponds to the 1975 income, after allowing for the modest inflation of the Sw.Fr. Fees from all categories of membership stood at $80 \%$ of the EPS income of which some $40 \%$ is contributed by the Individual Ordinary Members in categories $4 \mathrm{a}$ and 4c. There is a feeling that perhaps the relationship between the contributions of the $4 \mathrm{a}$ and $4 \mathrm{c}$ Members should now be reviewed and the delegates from the Individual Ordinary Members made a strong plea for an immediate reduction in the subscription of the $4 a$ category in particular. It was felt however that the structuring of the fees was something that needed to be studied rather more seriously as a complete package, rather than in the interest of one particular category and it was finally agreed that this review should be undertaken by the Executive Committee as a matter of priority.

It will be recalled that the unit fee is at present $7 \mathrm{Sw} . \mathrm{Fr}$. and that Council in Rome will have a motion before it to increase this figure to 8 Sw.Fr. The bylaws can be changed to modify the number of units payable by each category more rapidly than a change in Constitution requires.

There has been strict control of expenditure by the Geneva office and, with an almost fixed income, the annual surplus has necessarily decreased since 1975, so that allowing for a contribution to the special development fund of approximately 6000 Sw.Fr. it is expected that there will be no net surplus at the end of this year. In consequence, if the Society is to expand, measures must be taken to increase our income over and above the increase in unit fee, which will do no more than compensate for increased costs when it comes into force (assuming the Council approves) from the beginning of 1980 .

\section{Recruitment IOMs}

Essentially, therefore, the current financial situation is sound but stagnant and it seems evident that the key to expansion lies in an increase in the number of Individual Ordinary Members. There are a number of ways in which this can be done and a special sub-committee will study how best to coordinate the Society's efforts. It would seem that the main thrust must come from the national societies through publicity and from concerted efforts at conferences. It seems clear also that when national societies, as in France, are prepared to collect subscriptions to EPS at the same time as national subscriptions, this constitutes a considerable encouragement.

Surprisingly, even after 10 years, it is still not fully understood that membership of a national society does not mean automatically full membership of the European Physical Society. There is therefore a question of information to be tackled as well.

\section{Anniversary Celebrations}

The tenth anniversary of the European Physical Society was not allowed to pass without presentations being made to its President to commemorate the event.

The Institute of Physics of the UK as the host to the Fourth General Conference began with the presentation of a presidential gavel in ivory, followed by the French and the Italian Society each with a medal while INFN of Italy offered to print the proceedings of the Rome Conference free of charge. Good wishes were received also from other national societies.

The occasion was marked too, by the unanimous election of Professor H.B.G. Casimir and Professor V.K. Weisskopf to the position of Honorary Member. In addition, the opportunity was taken to make the presentation of the 1978 Hewlett-Packard Europhysics Prize to Zh.l. Alferov for his contribution to the development of practical heterojunctions.

Members were, moreover, invited also to make their own presentation to the Society in this year of its tenth anniversary. Not only in financial terms is the increase in Individual Ordinary Membership important, but in the whole strength and influence of the Society. It was suggested that each member should make his own contribution by finding at least one additional Individual Ordinary Member in the coming year. In this way the Society will be able to grow from within itself, independent of donations and other unearned income. 